\title{
Context effects in sentence comprehension: A reply to Doll and Lapinski
}

\author{
D. JAMES DOOLING and ROBERT E. CHRISTIAANSEN \\ Kent State University, Kent, Ohio 44242
}

\begin{abstract}
The view that context invariably speeds up the sentence comprehension process is challenged. In the normal comprehension of connected sentences in prose, subjects engage in schema construction activities. This is assumed to be a time-dependent process that is not carried out when isolated sentences are comprehended. There may be cases, therefore, where context would actually slow down the sentence comprehension process.
\end{abstract}

In a recent paper, Doll and Lapinsky (1974) measured the effects of various types of context on the speed of sentence comprehension. They found that context speeded up the sentence comprehension process. The results were interpreted within the framework of Bransford and Johnson's (1973) observation that thematic contexts help the subject to gain access to relevant prior knowledge that is needed for comprehension. In addition, the authors claimed that their results contradicted a conclusion of Dooling (1972):

"The present results therefore provide additional
evidence against the view ... that sentences are
encoded or their meanings realized without access to
nonlinguistic or world knowledge. Dooling's (1972)
view is succinctly illustrated by his statement that
"comprehending a sentence in context is a more
complex task than comprehending a sentence in
isolation.' On the contrary, the present results suggest
that less processing is often required to comprehend a
sentence in context than in isolation (p. 344)."

It is our contention that Doll and Lapinsky have seriously misinterpreted the Dooling (1972) paper and have ignored a critically important aspect of the context-sentence comprehension process.

In the Dooling (1972) experiment there were two sentence comprehension tasks. Task 1 required the subject to judge whether a sentence was meaningful and was meant to be representative of the type of processing involved in most sentence comprehension experiments. The Task 1 results supported the notion that context speeds up the comprehension process. One could say, with Doll and Lapinski, that context simplifies the process. But there was a second comprehension task in the Dooling study, and Doll and Lapinsky do not speak

Preparation of this paper was facilitated by a Summer Research Fellowship to the first author from Kent State University

Reprint requests should be sent to D. James Dooling, Psychology Department, Kent State University, Kent, Ohio 44242. of it. Task 2 required a different type of "comprehension." The subject had to judge whether the sentence was appropriate for the context. Under these conditions, longer contexts led to slower comprehension times. Task 2 was meant to be an analogue of the type of processing that goes on in the normal comprehension of prose. Subjects do not merely. "comprehend" individual sentences. They also construct an abstract representation of the theme of the passage. Presumably, such schema construction processes take time to perform. It was simply Dooling's contention that such integrative processing represents a case where context complicates the sentence comprehension process.

It is well established from memory experiments that the subjects recode individual sentences into some abstract form. Bransford and Franks (1971), for example, demonstrated that subjects integrate the meanings of various sentences into wholistic ideas. Dooling and Lachman (1971) have demonstrated that the "theme" of the passage is used as a mnemonic device. Sulin and Dooling (1974) have shown that the information in a prose passage is integrated with the subjects' preexperimental knowledge of the topic. The underlying explanations for these findings are not new, but can be traced directly to Bartlett's (1932) influential concept of the "schema." Now if the subjects come away from the comprehension of a prose passage with a "schema" or "theme," we are forced to assume that they have engaged in some form of schema construction process. Many authors have alluded to such a process, but no one has studied it systematically. For example, Bransford and Johnson (1973) speak of this type of comprehension in discussing the locus of inference effects: "These processes of making inferences and creating justifications probably occur quite frequently in the normal course of comprehending (p. 391)." They also seem to endorse the idea that schema construction occurs in the processing of prose:

"An input can be viewed as further information about some knowledge structure. The input may then cause a restructuring of (or an elaboration of) the old 
structure such that new information is acquired. The manner in which an input is related to a knowledge structure may thus influence the processes of knowledge acquisition (p. 429)."

More generally, in any treatment of "reading for meaning" there has to be some acknowledgement of the type of process that we are discussing. For example, Laberge and Samuels (1974) define "high-level comprehension" in terms of organizational processes that go beyond the meanings of individual sentences. It is simply our contention that such processes take time to perform. If we speak of comprehension in this sense then it is quite reasonable to assert that: "Comprehending a sentence in context is a more complex process than comprehending a sentence in isolation."

The main point of the Dooling (1972) paper, was that "comprehension" is not an unvarying, unitary process. In the processing of prose, there are various levels of comprehension (Mistler-Lachman, 1972, 1974). Humans are flexible processors of information and vary their endcoding strategies with the level of task demands (Craik \& Lockhart, 1972). From this perspective it is fruitless to claim that context has one particular effect on "comprehension." If the subjects have to recall unrelated sentences at a later time, then context (even misleading context) may help them encode the sentences for that purpose (Doll \& Lapinsky, 1974). If subjects have to judge the appropriateness of a sentence for a context, then increased context will lead to longer comprehension processes (Dooling, 1972). Unfortunately, neither of these tasks (nor any that we know of) even approximates the demands of "normal" reading for meaning. In cases where the subject needs only to come away from a paragraph with a vague general idea, we might assume that relatively little processing capacity is devoted to the analysis of sentence meanings and relatively more to schema construction processes. Unravelling these different types of comprehension is an incredibly complex task. Although there is widespread belief in the psychological reality of schemas, themes, and general ideas in the comprehension of prose, there has not yet been a single experimental study that has attempted to measure the time for such a process.

\section{REFERENCES}

Bartlett, F. C. Remembering. Cambridge, England: University Press, 1932.

Bransford, J. D., \& Franks, J. J. The abstraction of linguistic ideas. Cognitive Psychology, 1971, 1, 331-350.

Bransford, J. D., \& Johnson, M. K. Considerations of some problems of comprehension. In W. G. Chase (Ed.), Visual information processing. New York: Academic Press, 1973.

Craik, F. I. M., \& Lockhart, R. S. Levels of processing: A framework for memory research. Journal of Verbal Learning and Verbal Behavior, 1972, 11,671-684.

Doll, T. J., \& Lapinski, R. H. Context effects in speeded comprehension and recall of sentences. Bulletin of the Psych on omic Society, 1974, 3, 342-344.

Dooling, D. J. Some context effects in the speeded comprehension of sentences. Journal of Experimenta Psy chology, 1972, 93, 56-62.

Dooling, D. J., \& Lachman, R. Effects of comprehension on retention of prose. Journal of Experimental Psychology, $1971,88,216-222$.

LaBerge, D., \& Samuels, S. J. Toward a theory of automatic information processing in reading. Cognitive Psychology $1974,6,293-323$.

Mistler-Lachman, J. Levels of Comprehension in processing of normal and ambiguous sentences. Journal of Verbal Learning and Verbal Behavior, 1972, 11, 614-623.

Mistler-Lachman, J. Depth of comprehension and sentence memory. Journal of Verbal Learning and Verbal Behavior, $1974,13,98-106$.

Sulin, R. A., \& Dooling, D. J. Intrusion of a thematic idea in retention of prose. Journal of Experimental Psychology, $1974,103,255-262$.

(Received for publication November 25, 1974.) 